\title{
RECOVERY OF Y-CELLS IN THE LATERAL GENICULATE NUCLEUS OF MONOCULARLY DEPRIVED CATS ${ }^{1}$
}

\author{
E. E. GEISERT, ${ }^{2}$ PETER D. SPEAR, ${ }^{3}$ SONYA R. ZETLAN, AND A. LANGSETMO \\ Department of Psychology and Neurosciences Training Program, University of Wisconsin, Madison, Wisconsin 53706
}

Received September 25, 1981; Revised December 21, 1981; Accepted December 30, 1981

\begin{abstract}
Previous studies have demonstrated that removal of inputs from the nondeprived eye of monocularly deprived cats produces a recovery from some of the abnormalities caused by the deprivation. The present experiments examined whether the loss of Y-cells that occurs in the deprived laminae of the lateral geniculate nucleus (LGN) also can be reversed by this manipulation and, if so, what are the necessary and sufficient conditions for reversal to occur. Single cell recordings were made in LGN laminae A and A1 of 31 cats in a variety of rearing conditions, and the cells were classified as $\mathrm{X}, \mathrm{Y}$, or mixed on the basis of responses to a battery of tests.

In normal cats, a mean of $39.1 \%$ of the LGN cells were Y-cells. In agreement with previous studies, monocular deprivation produced a reduction in the proportion of Y-cells encountered (18.1\%). Removing the nondeprived eye at 4 months of age did not produce an increase in the proportion of $Y$-cells if the deprived eye remained closed for 3 months ( $16.9 \%)$. However, removing the nondeprived eye at 4 months and opening the deprived eye for 3 months did produce an increase in the proportion of Y-cells (40.2\%). Thus, the loss of Y-cells in the LGN that results from rearing with monocular deprivation can be reversed at 4 months of age; however, it is necessary to allow the deprived eye visual experience.

In a second experiment, we assessed the age limits and the conditions that are both necessary and sufficient for the recovery of Y-cells. Removing the nondeprived eye at 12 to 16 months of age and allowing the deprived eye 3 months of visual experience still produced a significant increase in the proportion of Y-cells (30.3\%). Thus, some reversal can occur well into adulthood. However, opening the deprived eye and simply closing the nondeprived eye (reverse suture) for 3 months in adult monocularly deprived cats did not produce a reversal of the LGN Y-cell loss (14.3\%). Thus, it is necessary both to allow the deprived eye visual experience and to remove the inputs from the nondeprived eye to produce a recovery of LGN Y-cells. Simply closing the nondeprived eye is not sufficient, even if the deprived eye is opened. Taken together with previous studies, these results also indicate that there is a dissociation between functional recovery in LGN and striate cortex and between recovery of LGN cell size and the functional class of Y-cells following removal of the nondeprived eye.
\end{abstract}

Monocular pattern vision deprivation has profound effects on the developing visual system of the cat. In striate cortex, there is a dramatic reduction in the number of cells that can be driven by the deprived eye (Wiesel

\footnotetext{
1 This work was supported by United States Public Health Service Postdoctoral Fellowship EY05259 (E. E. G.), United States Public Health Service Research Grants EY01916 and EY02545, and United States Public Health Service Research Career Development Award EY00089 (P. D. S.). We would like to thank Ms. Kathy Vielhuber and Ms. Stephanie Miller for their excellent technical assistance.

${ }^{2}$ Present address: Department of Anatomy, University of Alabama in Birmingham, University Station, Birmingham, AL 35294.

" To whom reprint requests should be addressed at Department of Psychology, University of Wisconsin, 1202 W. Johnson Street, Madison, WI 53706.
}

and Hubel, 1963b, 1965; Blakemore and Van Sluyters, 1974; Kratz et al., 1976; Shatz and Stryker, 1978). In the lateral geniculate nucleus (LGN), neurons in laminae receiving inputs from the deprived eye (deprived laminae) are smaller than neurons in nondeprived laminae or neurons in normal cats (Wiesel and Hubel, 1963a; Guillery and Stelzner, 1970; Hickey et al., 1977; Kalil, 1980). In addition, there is a marked reduction in the proportion of Y-cells encountered in physiological recordings from deprived laminae (Sherman et al., 1972, 1975).

Previous studies in our laboratory have demonstrated that removal of inputs from the nondeprived eye of monocularly deprived cats produces a recovery from some of the abnormalities caused by the deprivation. For example, there is a rapid increase in the ability of the 
deprived eye to drive neurons in striate cortex (Kratz et al., 1976). This increase occurs within a few hours and is unaltered by long survival times (over a year) or by allowing the deprived eye visual experience after the nondeprived eye inputs are removed (Smith et al., 1978; Kratz et al., 1976; Spear et al., 1980). In addition, removing the nondeprived eye causes neurons in deprived laminae of the LGN to grow to nearly normal size over a period of 3 months, and this growth occurs even when the deprived eye remains closed (Spear and Hickey, 1979). These and other observations suggest that some of the effects of monocular deprivation are due to interocular suppressive mechanisms and that the recovery after removal of the nondeprived eye is due to a release from this suppression (Kratz et al., 1976; Smith et al., 1978; Spear and Hickey, 1979; Spear et al., 1980).

The purpose of the present experiment was to determine if removal of inputs from the nondeprived eye also can produce a recovery from functional abnormalities in the LGN. Specifically, we wished to determine if Y-cells, which are reported to be lost after monocular deprivation, return to normal numbers along with the growth of cell size in the deprived laminae. In addition, we wished to assess the relationship between responses of LGN neurons and the recovery that occurs in responses of striate cortex neurons following removal of the nondeprived eye. By answering these questions, we hoped to learn more about possible sites and mechanisms of the effects of monocular deprivation and their reversal following removal of inputs from the nondeprived eye.

At the time that this investigation began, all of the studies that reported a loss of LGN Y-cells following monocular deprivation came from two laboratories (Sherman et al., 1972, 1975; Hoffmann and Cynader, 1977; Hoffmann and Holländer, 1978; Eysel et al., 1979; Sherman and Wilson, 1981). The only attempt to replicate these findings outside of these two laboratories did not find a loss of Y-cells in the LGN of monocularly deprived cats (Shapley and So, 1980). Therefore, in an initial experiment, we attempted to replicate the finding of a Y-cell loss. Concurrent with this, we determined if removal of the nondeprived eye with or without subsequent pattern vision through the deprived eye would produce a reversal of any $\mathrm{Y}$-cell loss that occurred. In a second experiment, we determined the age at which this reversal can occur and assessed the conditions that are necessary and sufficient for recovery.

\section{EXPERIMENT I}

\section{Materials and Methods}

Animals and rearing conditions. Twenty-four cats were divided into four groups: six normal adult cats, six 7-month-old monocularly deprived cats (MD), seven 7month-old monocularly deprived cats that had the nondeprived eye removed at 4 months of age (MD-DE), and five 7-month-old monocularly deprived cats that had the nondeprived eye removed and the deprived opened at 4 months of age (MD-DE-O). The ages and conditions used in this study are the same as those used to study LGN cell size (Spear and Hickey, 1979) and cortical physiology of monocularly deprived cats following removal of the nondeprived eye (Kratz et al., 1976; Smith et al., 1978). This allows for a direct comparison of our results and the results of those studies.

All deprived kittens were born in the laboratory breeding colony. Littermates were selected randomly to be in either the MD, MD-DE, or MD-DE-O groups with the restriction that no more than two animals from one litter were assigned to the same group. The kittens were housed with their mothers in individual cages until they were weaned. They then were moved to a large colony room with shelves and ramps for climbing. In all of the colony rooms, the light cycle was $18 \mathrm{hr}$ on and $6 \mathrm{hr}$ off. The normal adult cats were obtained from an outside vendor.

Lid suture and enucleation. Details of the procedures for lid suture and enucleation are presented elsewhere (Spear and Tong, 1980). The lids over one eye were sutured closed before normal eye opening had occurred. The lid margins were checked daily for openings throughout rearing. Most of the animals had no openings at any time before recording. If a small pin hole developed that was covered with mucus or underlying conjunctiva, it was repaired immediately. If an animal had an opening in the lid that allowed visualization of the cornea, the cat was excluded from the study.

Preparation for recording. The animals were anesthetized with Fluothane in $50 \% \mathrm{O}_{2}$ and $50 \% \mathrm{~N}_{2} \mathrm{O}$ for surgical procedures. A tracheotomy was performed and an endotracheal tube was inserted for artificial respiration. The animal was paralyzed by an intravenous injection of 40 mg of gallamine triethiodide (Flaxedil), followed by continuous infusion at a rate of $19 \mathrm{mg} / \mathrm{hr}$. End-expired $\mathrm{CO}_{2}$ was monitored with a Beckman LB-2 medical gas analyzer and maintained at $4 \%$ by adjusting the minute volume of the respirator. Small openings were made in the cranium over the LGN, the dura was reflected, and an agar/sucrose gel was applied to the exposed cortical surface. Bipolar stimulating electrodes were placed in the optic chiasm (OX) using a flash-evoked response as an indication of appropriate placement. The OX electrodes were placed at $\mathrm{AP}+15$ and $2 \mathrm{~mm}$ on either side of the midsagittal suture, with a depth of 21 to $24 \mathrm{~mm}$ below the dural surface. All wound edges were coated with a long acting local anesthetic (Anduracaine). Fluothane then was discontinued and the animal was maintained under $75 \% \mathrm{~N}_{2} \mathrm{O}$ and $25 \% \mathrm{O}_{2}$ for recording. Body temperature was kept at $38^{\circ} \mathrm{C}$ with a heating pad, and the heart rate was monitored continuously.

The pupils were dilated by topical application of $1 \%$ atropine sulfate. The corneas were protected by contact lenses containing a 3 - or 4-mm-diameter artificial pupil. A translucent tangent screen was placed $114 \mathrm{~cm}$ from the approximate nodal point of the eye. The eyes were refracted and the optic discs were plotted on the tangent screen using the method of Fernald and Chase (1971). The position of the area centralis was determined from the optic disc plots (Nikara et al., 1968).

Recording. Single cell activity was recorded extracellularly with varnish-coated tungsten microelectrodes. The electrodes were dipped into the varnish tip first so that there was no exposed tip. Electrode impedance was 6 to 8 megohms measured with a $0.5-\mathrm{msec}$ square wave input and 50 to 80 megohms measured with a $135-\mathrm{Hz}$ sine wave input. The electrode was advanced slowly in 3 - to 
$5-\mu \mathrm{m}$ steps through the LGN while searching for isolated single cells. During the search procedure, spots of light were moved and flashed on the tangent screen. Once a penetration was started through a lamina, it was terminated only after the lamina was completely traversed. Recordings were made from both laminae $\mathrm{A}$ and $\mathrm{A} 1$; in deprived animals, only the deprived laminae were studied. Action potentials thought to arise from cell bodies were distinguished from axon spikes by the criteria described by Bishop et al. (1962), and the present results concern cell body recordings only. To mark the location of the last penetration on each side of the brain, small electrolytic lesions were made in the LGN.

Visual stimulation. Visual stimuli were presented on the tangent screen with a hand-held projector or with an automated projector system. For mapping visual receptive fields, the tangent screen was illuminated diffusely at $-1.36 \mathrm{log} \mathrm{cd} / \mathrm{m}^{2}$ and spots of light from -0.88 to 0.3 $\log \mathrm{cd} / \mathrm{m}^{2}$ were used. In addition, a variety of stimuli were available for classifying cells as X or Y (see below). For testing velocity sensitivity, either a spot of light $(0.04$ $\left.\log \mathrm{cd} / \mathrm{m}^{2}\right)$ on a dark background $\left(-1.36 \log \mathrm{cd} / \mathrm{m}^{2}\right)$ or a dark spot $\left(-1.24 \log \mathrm{cd} / \mathrm{m}^{2}\right)$ on a light background $(0.04$ $\log \mathrm{cd} / \mathrm{m}^{2}$ ) was moved back and forth across the receptive field. In each case, the spot was $3.5^{\circ}$ in diameter. For testing the linearity of spatial summation, a $6.5^{\circ}$-diameter bipartite field was used. The luminance of each halffield was modulated sinusoidally $180^{\circ}$ out of phase so that the overall mean luminance of the stimulus remained constant. The luminance of each half-field of the stimulus varied between -0.46 and $-1.30 \log \mathrm{cd} / \mathrm{m}^{2}$.

Classification of cells. Four main tests were used to classify cells as X, Y, or mixed. These tests were receptive field center size, cutoff velocity, linearity of spatial summation, and response latency to $\mathrm{OX}$ stimulation. These tests were chosen because they are objective and quantitative, and previous studies have shown that they reliably discriminate between functional classes of lateral geniculate neurons (Cleland et al., 1971; Hoffmann et al., 1972; Shapley and Hochstein, 1975; Bullier and Norton, 1979). The nature of each of these tests is described in detail below, and responses of X-and Y-cells to each test are illustrated in Figure 1.

Receptive field centers were plotted with small, dim spots of light flashed on and off. The area within which stimulation evoked a consistent center type (on or off) response was drawn on the tangent screen and the mean diameter (average of major and minor axes for elliptical receptive fields) was measured in degrees of arc.

Velocity sensitivity was determined by moving a $3.5^{\circ}$ spot back and forth across the receptive field. A dark spot was used for on-center cells and a light spot was used for off-center cells. The stimulus sweep was $13^{\circ}$ in each direction. Stimulus velocity and repetition rate were co-varied because our purpose was to replicate previously published tests to distinguish cell types rather than to obtain a pure measure of velocity sensitivity. Using the automated projector system, the velocity was increased steadily and the maximum value to which the cell responded on every stimulus sweep was determined (cutoff velocity).

The presence of linear or nonlinear spatial summation was tested with the bipartite field stimulus. A complete phase reversal of each half-field repeated at a rate of 1 $\mathrm{Hz}$. This stimulus was stepped across the receptive field to find a location at which no response (linear summation) or response doubling (nonlinear summation) occurred for the cell.

Latency to OX stimulation was tested with electrical stimuli repeated at a rate of 0.5 to $1 / \mathrm{sec}$. Using a storage oscilloscope, modal latency was measured from the beginning of the stimulus pulse to the foot of the action potential.

All four tests were carried out for nearly all of the cells;

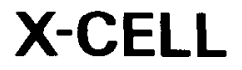

A
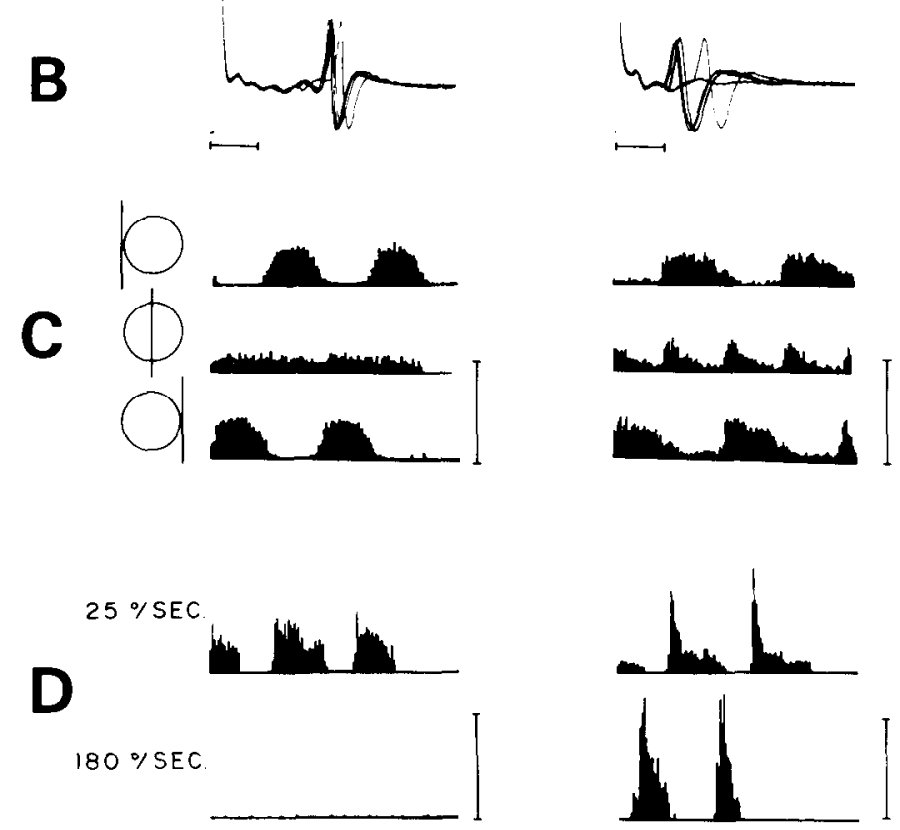

Figure 1. Examples of responses to the four tests used to classify cells as $\mathrm{X}$ or $\mathrm{Y}$. The responses of a typical X-cell are shown on the lefl and those of a typical Y-cell are on the right. $A$, Receptive field centers plotted with a small flashed spot of light. The receptive field center diameter was $0.68^{\circ}$ for the $\mathrm{X}$ cell and $1.65^{\circ}$ for the Y-cell. $B$, Latency to optic chiasm stimulation. Storage oscilloscope traces are shown, and the responses to five optic chiasm shocks are superimposed. The scale bar is $1 \mathrm{msec}$ and is aligned with the stimulus onset. Modal latency was $2.3 \mathrm{msec}$ for the X-cell and $1.1 \mathrm{msec}$ for the Y-cell. $C$, Spatial summation. The responses of the 2 neurons to a phasereversing bipartite field are illustrated by three sets of poststimulus time histograms. The bin width is $10 \mathrm{msec}$ and the scale bar represents 100 spikes/bin. On the left, the circle represents the receptive field center and the vertical line represents the division of the bipartite field. In the middle trace, the X-cell demonstrated a null point and the Y-cell showed response doubling. $D$, Maximum cutoff velocity. The responses of 2 neurons are illustrated in two sets of poststimulus time histograms. The bin width is $10 \mathrm{msec}$ for the $25^{\circ} / \mathrm{sec}$ histograms and $2 \mathrm{msec}$ for the $180^{\circ} / \mathrm{sec}$ histograms. The scale bar represents 100 spikes/bin. The X-cell responded at low velocities $\left(25^{\circ} / \mathrm{sec}\right)$ but not at high velocities $\left(180^{\circ} / \mathrm{sec}\right)$, while the Y-cell responded to both low and high velocities. For further details see "Materials and Methods." 
however, a few cells failed to respond to the phasereversing bipartite field in any receptive field location or failed to respond to $\mathrm{OX}$ stimulation. For these cells, classification was based upon three tests. Cells were classed as X if they had at least three out of four (or two out of three) of the following properties: $<1.0^{\circ}$ receptive field center diameter, $<160^{\circ} / \mathrm{sec}$ maximum velocity, linear spatial summation, and OX latency $>1.6 \mathrm{msec}$. Cells were classified as $Y$ if they had at least three out of four (or two out of three) of the opposite properties. Cells were classified as mixed if they responded as an X-cell on two tests and as a Y-cell on the remaining two tests. ${ }^{4}$

Histology. Following the recording session, the animals were injected with a lethal dose of sodium pentobarbital and perfused through the heart with normal saline followed by $10 \%$ formalin in normal saline. For each animal, a single block of tissuc containing both LGNs was processed for celloidin embedding, and serial sections were cut coronally at $52 \mu \mathrm{m}$. From this series, every other section was mounted on slides and stained with cresyl violet. To assure that the data were collected from the laminae $A$ and $A 1$ of the $L G N$, the location of each electrolytic lesion and penetration was plotted. Nearly all data were from neurons verified to be in laminae $A$ or A1. However, in one animal, seven penetrations could not be found. Since the changes in retinotopic location of the receptive fields seen when the electrode was moved from one penetration to another were appropriate to the retinotopic map of the LGN (Sanderson, 1971) and since the response properties of these cells were like those of LGN neurons, the data from these seven penetrations were included in the study.

\section{Results}

Extracellular recordings were made from 553 LGN neurons: 151 neurons in normal animals, 126 neurons from $\mathrm{MD}$ animals, 145 neurons from MD-DE animals, and 131 neurons from the MD-DE-O animals. From 12 to 37 neurons were recorded in each animal. All neurons were within $29^{\circ}$ of area centralis with $95.3 \%\left({ }^{527} / 553\right)$ having receptive fields between 2 to $20^{\circ}$ of area centralis and $69.1 \%(382 / 553)$ having receptive fields between 5 to $15^{\circ}$ of area centralis. The eccentricity distributions of the receptive fields were similar in all four groups.

Normal cats. Most neurons could be classified unambiguously as either X-or Y-cells. Only a few neurons had mixed properties or did not respond to a sufficient number of tests to allow classification (nonclassifiable cells). The percentage of cells in each class for lamina $A$ and lamina A1, pooled across animals, is summarized in the upper part of Table I. The Y-cells comprised $40.4 \%(61 / 151)$ of the neurons encountered in normal animals, and the proportion of Y-cells in lamina A1 $(45.6 \%)$ was somewhat higher than that seen in lamina $\mathrm{A}(34.7 \%)$. The mean and standard error of the percentage of $\mathrm{Y}$-cells among individual normal animals are shown in Figure 2. The lowest

\footnotetext{
${ }^{4}$ For all results that are reported, the conclusions are the same if a more stringent criterion was adopted for classifying $\mathrm{X}$ - and $\mathrm{Y}$-cells. That is, classifying as $\mathrm{Y}$-cells only those that met the appropriate criterion on all tests did not alter the between group differences that are reported.
}

TABLE I

Percentage of lateral geniculate nucleus neurons in each receptive field class for each group of cats

\begin{tabular}{lccccc|cccccc}
\hline \multirow{1}{*}{ Condition } & \multicolumn{4}{c|}{ Lamina A } & \multicolumn{5}{c}{ Lamina A1 } \\
\cline { 2 - 10 } & $\begin{array}{l}\text { No. } \\
\text { Cells }\end{array}$ & $\mathrm{Y}^{a}$ & $\mathrm{X}$ & $\mathrm{M}$ & $\mathrm{NC}$ & No. & $\mathrm{Y}$ & $\mathrm{X}$ & $\mathrm{M}$ & $\mathrm{NC}$ \\
& & \multicolumn{4}{c}{$\%$} & & \multicolumn{5}{c}{$\%$} \\
Normal & 72 & 34.7 & 56.9 & 5.6 & 2.8 & 79 & 45.6 & 50.6 & 3.8 & 0 \\
MD & 84 & 19.1 & 69.0 & 9.5 & 2.4 & 42 & 21.4 & 69.1 & 9.5 & 0 \\
MD-DE & 64 & 15.6 & 75.0 & 6.3 & 3.1 & 81 & 18.5 & 67.9 & 9.9 & 3.7 \\
MD-DE-O & 67 & 25.4 & 64.1 & 9.0 & 1.5 & 64 & 54.7 & 40.6 & 3.1 & 1.6 \\
& & & & & & & & & & & \\
Adult MD-DE-O & 61 & 29.5 & 57.3 & 6.6 & 6.6 & 70 & 32.8 & 58.6 & 5.8 & 2.8 \\
Adult MD-RS & 41 & 14.7 & 78.0 & 4.8 & 2.5 & 50 & 14.0 & 80.0 & 6.0 & 0
\end{tabular}

" Y, Y-cells; X, X-cells; M, cells with mixed X and Y properties; NC, cells that responded too poorly to allow classification (nonclassifiable).

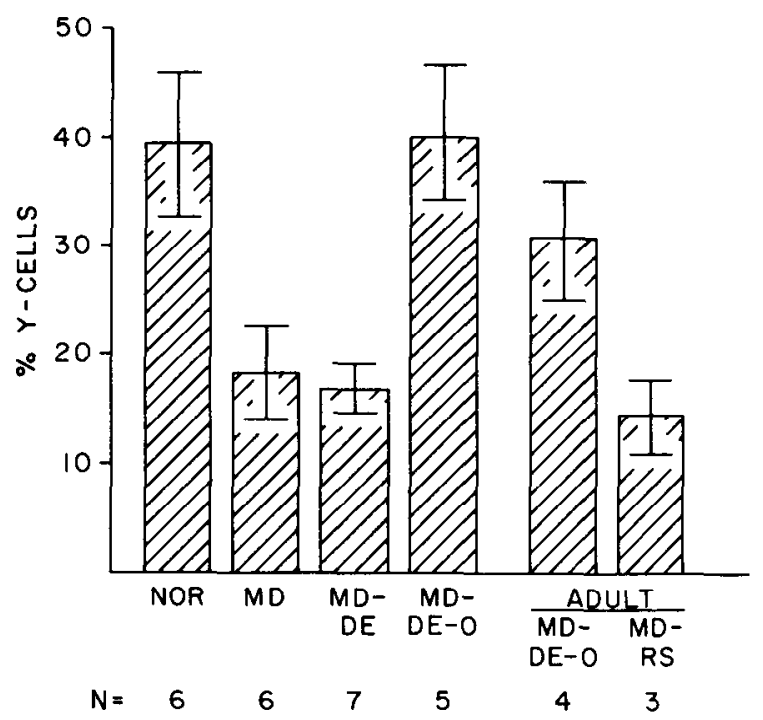

Figure 2. Percentage of $\mathrm{Y}$-cells encountered in recordings from the lateral geniculate nucleus. Results from experiment I are shown by the four bars on the left, and results from experiment II are shown by the two burs on the right. The abbreviations used are: NOR, normal animals; MD, monocularly deprived cats; MD-DE, monocularly deprived cats that had the nondeprived eye removed; MD-DE-O, monocularly deprived cats that had the nondeprived eye removed and the deprived eye opened; ADULT MD-DE-O, monocularly deprived cats that had the nondeprived eye removed and the deprived eye opened as adults; ADULT MD-RS, monocularly deprived cats that were reverse sutured as adults. The bars represent the means and brackets represent standard errors of the percentage of $\mathrm{Y}$-cells encountered among individual animals. Results from layers $\mathrm{A}$ and $\mathrm{Al}$ are combined for each cat. $N$, The number of animals in each group.

percentage of $\mathrm{Y}$-cells seen in any normal animal was $21.4 \%$, while the highest was $58.8 \%$. The mean percentage of Y-cells for the group was $39.1 \%$.

Frequency distributions of the responses of normal neurons to each of the four tests used to classify cells are shown in Figures 3 to 6 . The cell classification shown in these figures (solid, open, and cross-hatched bars) is based on all four tests, and the criterion for defining $\mathrm{X}$ and $\mathrm{Y}$-cells on each of the tests is indicated by an arrow on the abscissa. When the percentage of $\mathrm{Y}$-cells was 

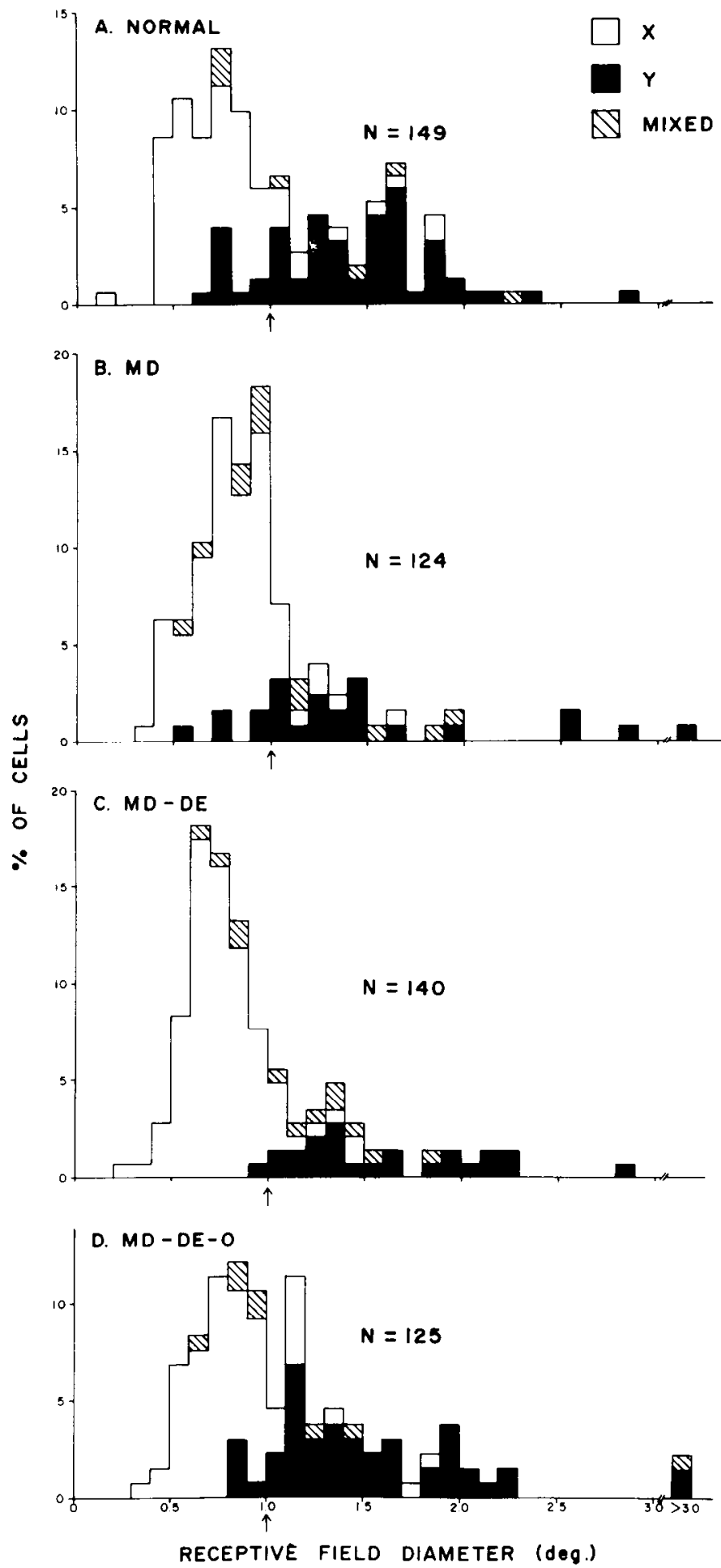

Figure 3. Frequency distribution of receptive field center diameters for LGN neurons in normal cats $(A)$, MD cats $(B)$, MD-DE cats $(C)$, and MD-DE-O cats $(D)$. The histograms show the percentage of cells with each receptive field center diameter (abscissa). The arrow on each abscissa shows the criterion used to classify cells as $\mathrm{X}$ or $\mathrm{Y}$ with this test (see "Materials and Methods"). The open, solid, and cross-hatched portion of each histogram shows the proportion of cells that were classified as X, Y, or mixed using all four tests. Cells that responded so poorly on all tests that they could not be classified are not shown. $N$ indicates the total number of cells for which receptive fields were measured in each condition. determined on the basis of each of the four tests individually, there was good agreement among individual tests.

$M D$ cats. The percentage of cells in each class for lamina A and lamina A1 of monocularly deprived cats is summarized in Table I. Overall, $19.8 \%\left({ }^{25 / 126)}\right.$ were Y-cells and, as in normal cats, the percentage of $\mathrm{Y}$-cells in lamina Al (21.4\%) was somewhat higher than that seen in lamina A $(19.1 \%)$. The mean and standard error of the percentage of Y-cells ranged from $8.3 \%$ to $34.5 \%$ in individual cats, and the mean for the group was $18.1 \%$. The percentage of $\mathrm{Y}$-cells seen in the MD group was significantly lower than that seen in the normal group $(U=4 ; p=$ 0.013 , one-tail, Mann-Whitney test). Thus, there was a loss of Y-cells encountered in the laminae receiving input from the deprived eye in cats reared with one eye sutured closed.

The decrease in the proportion of Y-cells also was seen in each of the four individual tests. By comparing the data from the normal group to that of the MD group, the decrease in the number of cells that would be classified as Y-cells on each of the four tests is apparent in Figures 3 to 6 . Thus, the loss of Y-cells in monocularly deprived cats was seen independent of the means of classification, whether a battery of tests was used or any one of the four individual tests was used. In addition, the changes seen in the percentage of $\mathrm{Y}$-cells were due to an alteration of all four response properties, not only a few.

Along with the loss of Y-cells, there was an increase in the percentage of all other cell types (see Table I). The ratio of mixed to $\mathrm{X}$-cells seen in monocularly deprived animals was similar to that seen in normal cats, suggesting that the effects of monocular deprivation were specific to the $\mathrm{Y}$-cells. This issue was addressed directly by comparing the sampling density of $\mathrm{X}$-cells and $\mathrm{Y}$-cells seen in normal animals to that seen in monocularly deprived cats. The encounter rate (the average number of cells encountered on one penetration through one lamina) was calculated for X-and Y-cells for animals in each group. There was no difference in the encounter rate between the two groups for X-cells; in both normal and monocularly deprived animals, an average of $2.2 \mathrm{X}$ cells was encountered in a single penetration through one lamina. However, in monocularly deprived cats, the encounter rate for Y-cells ( 0.7 cell/lamina) was lower than that seen in normal animals ( 1.5 cells/lamina). Thus, it appears that, while there was a loss of Y-cells, the number of X-cells remained normal in monocularly deprived cats.

$M D-D E$ cats. Data were collected from seven monocularly deprived cats that had their nondeprived eye removed at 4 months of age (MD-DE). The deprived eye remained closed for the ensuing 3 months. The percentage of each cell type in lamina $A$ and lamina $A 1$ is shown in Table I. The Y-cells comprised $17.2 \%(25 / 145)$ of the cells encountered in the MD-DE cats. The proportion of $Y$ cells in lamina A1 (18.5\%) was again higher than that found in lamina $A(15.6 \%)$. The mean and standard error of the percentage of $\mathrm{Y}$-cells among individual MD-DE cats are illustrated in Figure 2. The lowest percentage of $Y$-cells seen in any animal in the MD-DE group was $12.5 \%$ and the highest was $25 \%$. The mean percentage for the MD-DE group was $16.9 \%$. This was significantly lower than that seen in normal animals $(U=2 ; p=$ 

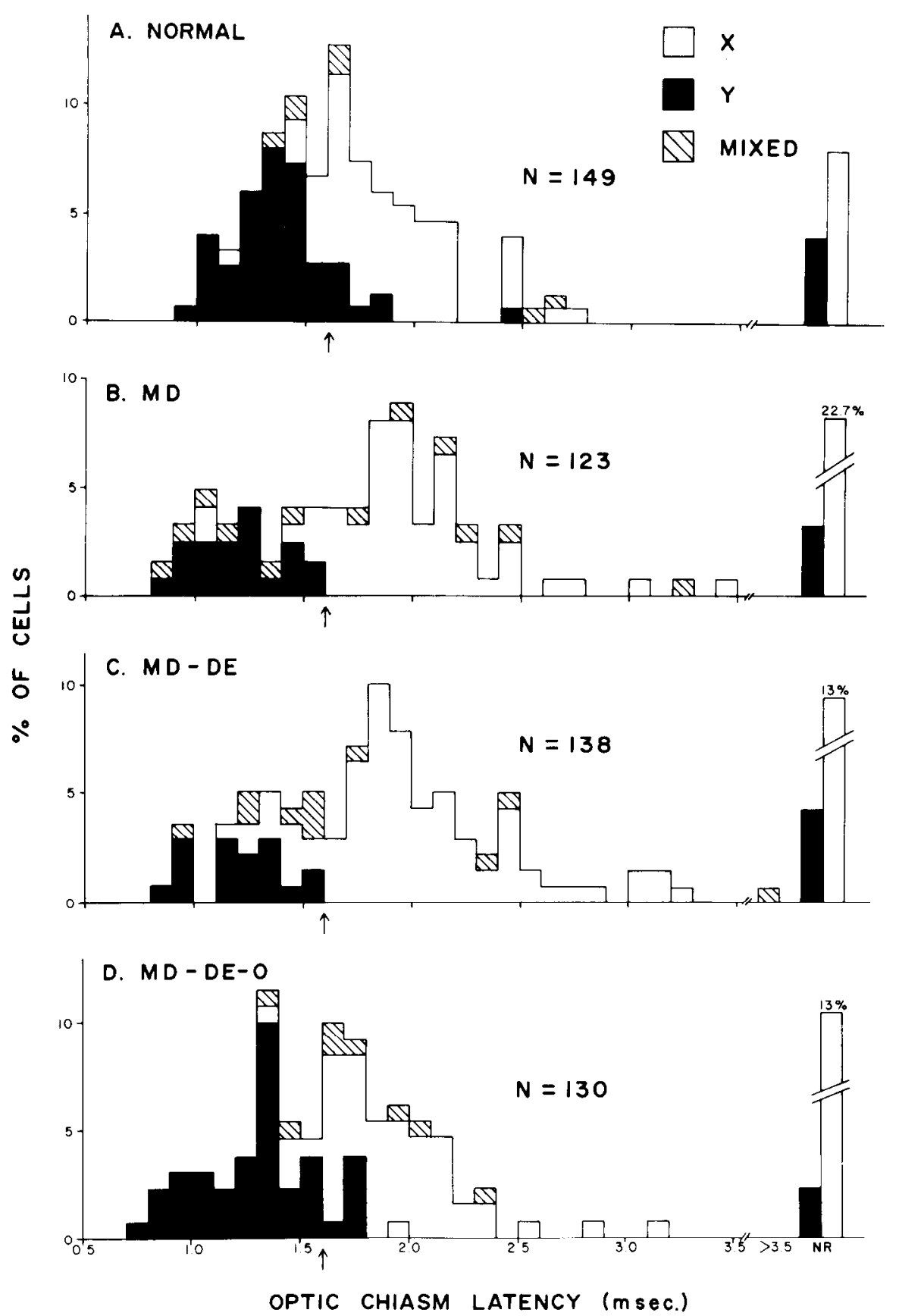

Figure 4. Frequency distribution of modal response latency to electrical stimulation of the optic chiasm for LGN neurons in normal cats $(A), \mathrm{MD}$ cats $(B)$, MD-DE cats $(C)$, and MD-DE-O cats $(D)$. The histograms show the percentage of cells with each modal response latency (abscissa). The arrow on each abscissa shows the criterion used to classify cells as X or $\mathrm{Y}$ with this test (see "Materials and Methods"). NR indicates cells that did not respond to optic chiasm stimulation. Other conventions are as in Figure 3.

0.002 ) but indistinguishable from that observed in monocularly deprived cats.

The frequency histograms for the four individual tests of the MD-DE animals showed a distribution similar to that seen in the monocularly deprived cats (Figs. 3 to 6). Therefore, the findings on each of the individual tests demonstrated the same result as the classification using a battery of tests to define X-and Y-cells.

As in MD animals, there was an increase in the percentage of other cell types along with the loss of $\mathrm{Y}$-cells in $\mathrm{MD}-\mathrm{DE}$ cats. The relative proportion of mixed to $\mathrm{X}$ cells also was similar to that seen in both normal and $\mathrm{MD}$ cats. In addition, the encounter rate for $\mathrm{X}$-cells (2.3 cells/lamina) was similar to that seen in both the normal cats and the monocularly deprived cats. In contrast, the encounter rate for Y-cells in the MD-DE group ( 0.6 cell/ lamina) was lower than that seen in normal animals but comparable to that seen in the MD group. Therefore, all indicators demonstrated that no recovery in the $\mathrm{Y}$-cell population occurred in MD-DE animals. 


\section{A. NORMAL}
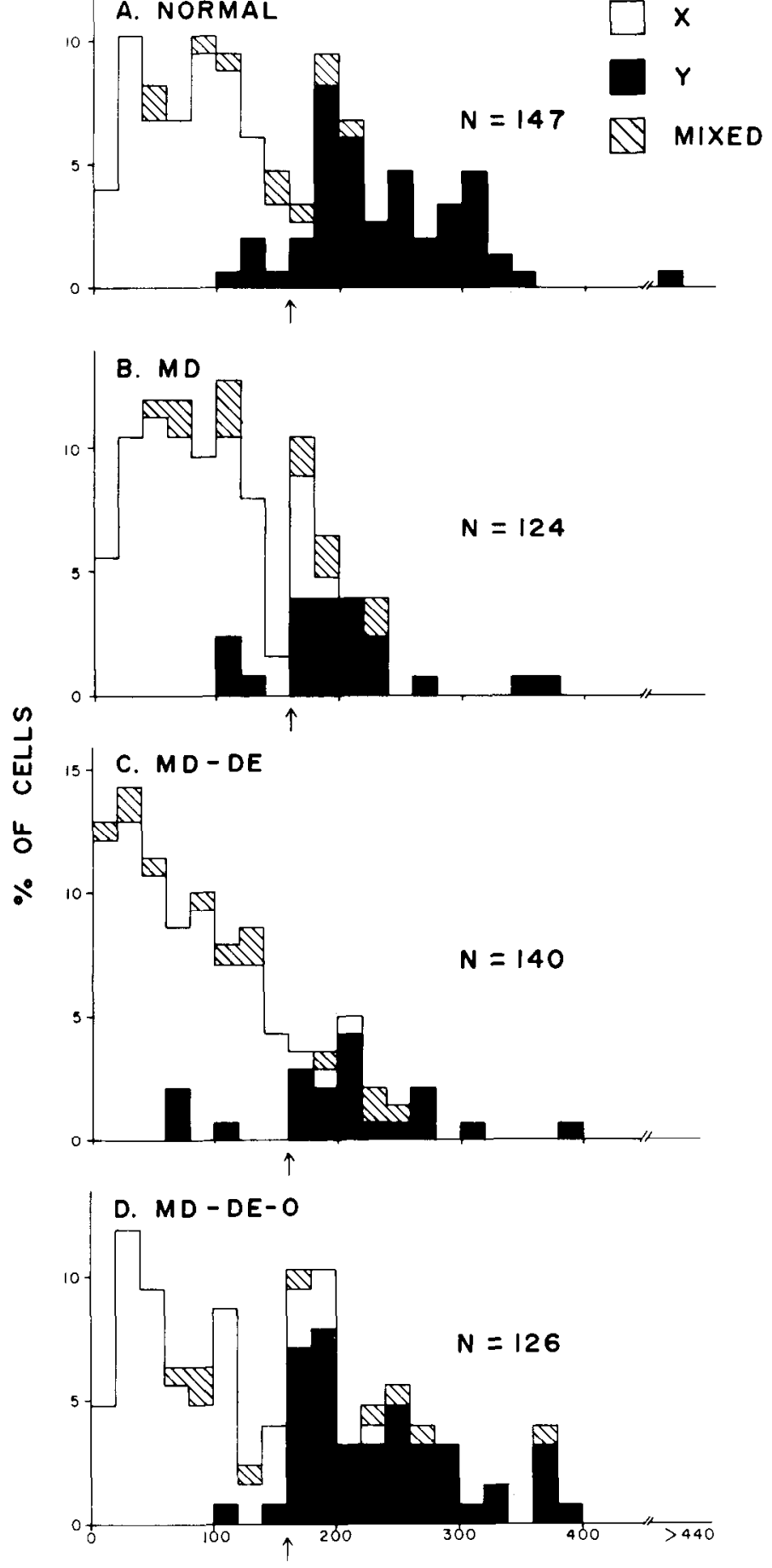

CUTOFF VELOCITY (deg./sec.)

Table I. The Y-cells comprised 39.7\% (52/131) of the neurons encountered in the MD-DE-O cats. The proportion of Y-cells in lamina A1 (54.7\%) was higher than that in lamina A (25.4\%). The mean and standard error of the percentage of Y-cells among individual MD-DE-O animals are illustrated in Figure 2. The percentage of Y-cells ranged from $26.3 \%$ to $54.5 \%$ in individual animals, and the mean percentage of Y-cells for the group was $40.2 \%$. The percentage of Y-cells found in the MD-DE-O group was significantly higher than that seen in either MD animals $(U=2 ; p=0.009)$ or the MD-DE animals ( $U$ $=0 ; p=0.001$ ) but indistinguishable from the proportion of Y-cells seen in normal animals. 'Thus, there was a recovery of the $\mathrm{Y}$-cell population when the nondeprived eye was removed and the deprived eye was opened.

The results from the MD-DE-O group on each of the four individual tests (Figs. 3 to 6 ) also demonstrate that the percentage of Y-cells increased relative to either the monocularly deprived group or the MD-DE group. On each of the four tests, the increase in the proportion of neurons that were classified as Y-cells can be seen, and the distribution of responses for the MD-DE-O group was similar to that of the normal group. Therefore, independent of the means of classification, the same result was observed.

The overall properties of the population of Y-cells in MD-DE-O cats were similar to the properties of Y-cells of normal animals. When using a battery of tests to classify cells as either $\mathrm{X}$ or $\mathrm{Y}$, we found that some neurons responded on three tests as one type of cell but, on a fourth test, like the other type of cell. For example,

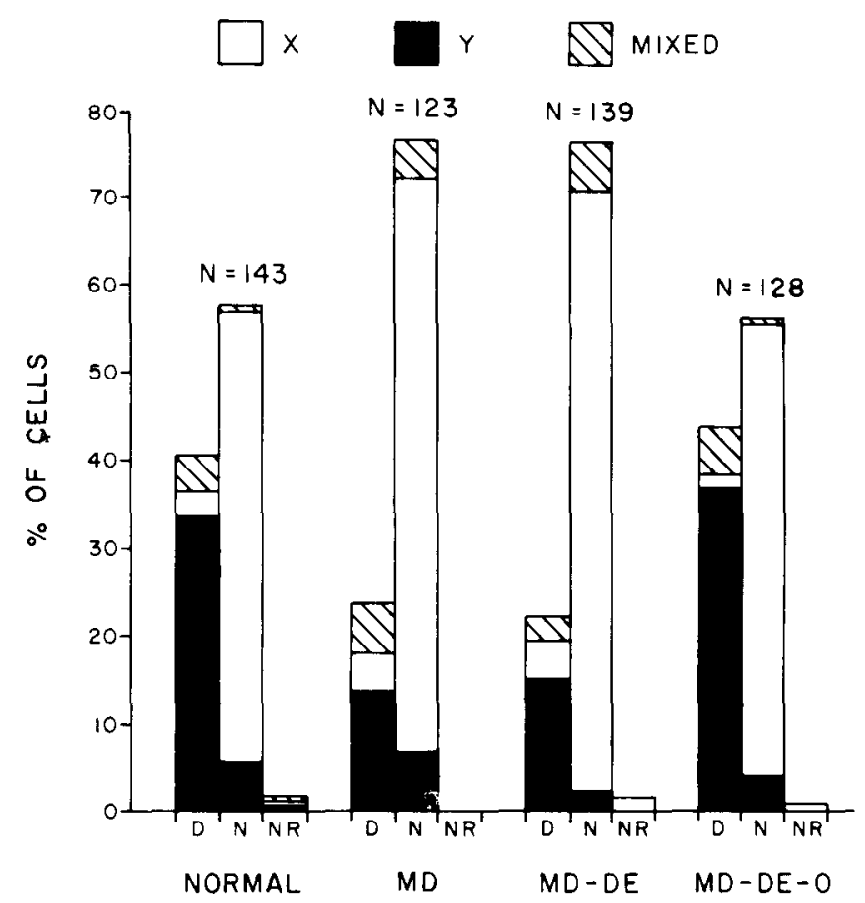

Figure 6. Frequency distribution of responses of LGN neurons to the test for linearity of spatial summation (see "Materials and Methods" for description of test). Results are shown for normal cats, MD cats, MD-DE cats, and MD-DE-O cats. The bars show the percentage of cells with nonlinear spatial summation ( $D$, response doubling), linear spatial summation ( $N$, null point), or no response $(N R)$ to the bipartite field stimulus. Other conventions are as in Figure 3. 
a cell might respond like a Y-cell on three tests and like a $\mathrm{X}$-cell on the remaining test. To compare the population of Y-cells found in MD-DE-O animals to that of normal cats, we determined the percentage of $Y$-cells that responded as Y-cells on all four tests (perfect Ycells) in normal and MD-DE-O cats. There was no significant difference in the percentage of perfect Y-cells between the normal (48\%) and the MD-DE-O (67\%) groups. Therefore, by every measure available to us, the population of Y-cells in the MD-DE-O cats was similar to that seen in the normal cats.

The percentage of the other types seen in MD-DE-O animals also was similar to that seen in normal cats (see Table I). In addition, the encounter rates for both X-cells (1.9 cells/lamina) and Y-cells (1.35 cells/lamina) were similar to those seen in normal animals. Therefore, not only did the percentage of Y-cells increase when the nondeprived eye was removed and the deprived eye was opened but there appeared to be a complete recovery of their sampling density as well.

\section{EXPERIMENT II}

In the first portion of this study, we demonstrated that, when the nondeprived eye is removed and the deprived eye is opened in 4-month-old monocularly deprived cats, there is a recovery of the $\mathrm{Y}$-cell population. A recent experiment (Mangel et al., 1980) indicates that the LGN is not completely developed at this age. Therefore, the recovery seen in these animals may be due to residual developmental processes. In addition, it is possible that removal of the nondeprived eye is not necessary for the reversal to occur and that opening the deprived eye alone is sufficient for this recovery. To address both of these issues, we recorded from the LGN of two additional groups of animals. The first group was reared with monocular deprivation for over 1 year and then the nondeprived eye was removed and the deprived eye was opened for 3 months (adult MD-DE-O). This group provides an assessment of whether the plasticity seen in the LGN at 4 months of age is still present in adult animals. The second group of animals was reared with monocular deprivation and, at 16 months of age, the animals were reverse sutured for 3 months (adult MD$\mathrm{RS}$ ). This second group of cats provides an assessment of whether removal of the nondeprived eye is necessary and whether opening the deprived eye is sufficient for the recovery.

\section{Materials and Methods}

Seven monocularly deprived cats 1 year or more of age were used. Four of these cats had the nondeprived eye removed and the deprived eye opened when the animals were from 12 to 16 months old (adult MD-DE-O). 'The other three had the initially nondeprived eye sutured closed and the initially deprived eye opened (reverse suture) at 16 months of age (adult MD-RS). Both groups of cats then were allowed to survive for 3 months before single cell recordings were made from the LGN. All other methods were identical to those used in experiment I.

\section{Results}

Adult MD-DE-O cats. The percentage of each cell type for lamina A and lamina AI of adult MD-DE-O cats is summarized in the lower part of Table I. The proportion of Y-cells pooled over all cats was $31.3 \%\left({ }^{41 / 131)}\right)$. The mean and standard error of the percentage of Y-cells among individual cats are shown in Figure 2. The percentage of Y-cells ranged from $17.2 \%$ to $39.3 \%$, with a mean for the adult MD-DE-O group of $30.3 \%$. This was significantly higher than the percentage of $\mathrm{Y}$-cells in MD-DE animals $(U=3 ; p=0.021)$ and marginally different from MD cats ( $U=5 ; p=0.086$ ). On the other hand, the percentage of Y-cells in adult MD-DE-O animals was not significantly different from MD-DE-O ( $U$ $=6 ; p=0.206)$ or normal $(U=9 ; p=0.305)$ animals.

On each of the individual tests, the results were similar to those seen for the MD-DE-O and normal groups. In addition, the percentage of other $(\mathrm{X}$, mixed, and nonclassifiable) cell types, the encounter rate for X-cells $(2.27$ cells/lamina), and the encounter rate for Y-cells (1.27 cells/lamina) of the adult MD-DE-O group were all similar to those seen in the MD-DE-O and normal groups. Thus, the plasticity seen in the LGN of 4-month-old monocularly deprived cats still was present in adult monocularly deprived cats.

Adult MD-RS cats. In the reverse sutured cats, the percentage of Y-cells was $14.3 \%(13 / 91)$. The percentage of each cell type for lamina $\mathrm{A}$ and lamina $\mathrm{Al}$ pooled over all cats is summarized in Table $I$ and the mean and standard error of the percentage of $\mathrm{Y}$-cells for individual animals are shown in Figure 2. The percentage of Y-cells ranged from $11.4 \%$ to $20.0 \%$ in individual cats, with the mean percentage for the group being $14.3 \%$. The percentage of Y-cells in the MD-RS cats was significantly lower than that seen in normal cats $(U=0 ; p=0.012)$, MD-DE-O cats ( $U=0 ; p=0.018)$, and adult MD-DE-O cats $(U=1 ; p=0.057)$ but indistinguishable from that seen in either the MD cats or the MD-DE animals.

On each of the individual tests, the results were similar to those seen in both the MD and MD-DE groups. The encounter rate for $\mathrm{X}$-cells $(2.4$ cells/lamina) and the encounter rate for Y-cells $(0.43$ cell/lamina) in the reverse sutured animals were all similar to those seen in the monocularly deprived cats. Thus, no recovery from the effects of monocular deprivation occurred in the reverse sutured cats.

\section{Discussion}

We have shown that, in monocularly deprived cats, there is a loss of Y-cells in the laminae of the LGN receiving input from the deprived eye, replicating the original finding of Sherman et al. (1972). Furthermore, we have demonstrated that, under the appropriate conditions, this loss of Y-cells can be reversed. For this recovery from the effects of monocular deprivation to occur, it is necessary for both the nondeprived eye to be removed and the deprived eye to be opened; neither alone is sufficient. We also have shown that this reversal of the Y-cell loss can occur in adult monocularly deprived cats, demonstrating the plasticity of the LGN even in adult animals.

Normal cats. In normal cats, we found that $39 \%$ of the neurons encountered in the A laminae of the LGN are $\mathrm{Y}$-cells. This is in agreement with the percentage of $\mathrm{Y}$ cells found by most other investigators using extracellular recording methods (Cleland et al., 1971; Hoffmann et al., 
1972; Wilson et al., 1976; Bullier and Norton, 1979) and intracellular recording methods (Friedlander et al., 1981). Furthermore, Friedlander et al. (1981) make a very strong argument that this is close to the true percentage of $\mathrm{Y}$ cells in the A laminae. In one recent study (Shapley and So, 1980), the percentage of Y-cells found in the lateral geniculate nuclei was extremely low. This discrepancy may be due to the electrodes used by these authors or to other variations in techniques (see review by Sherman and Spear, 1982).

$M D$ cats. In the LGN of monocularly deprived cats, we found a loss of Y-cells in the laminae that receive input from the deprived eye. Similar results were seen with all four tests that we used to classify cells. Therefore, the loss of Y-cells is not due to change or loss only of particular response properties. Rather, a class of cells with a group of correlated properties appears to be affected. In addition, sampling density measures indicated that there is no effect on the proportions of other cell types (e.g., X-cells).

This loss of Y-cells confirms previous studies that used similar methods (Sherman et al., 1972, 1975; Hoffmann and Cynader, 1977; Hoffman and Holländer, 1978; Eysel et al., 1979; Sherman and Wilson, 1981; Mower et al., 1981). In addition, it is supported by anatomical studies (LeVay and Ferster, 1977; Garey and Blakemore, 1977; Lin and Sherman, 1978) and by physiological studies using very different methods (Mitzdorf and Singer, 1980; Jones, 1980; Friedlander et al., 1982). However, Shapley and So (1980) failed to observe a loss of Y-cells when recording from single neurons in the deprived laminae. The reasons for their negative findings are not immediately apparent (for a detailed discussion, see Sherman and Spear, 1982); however, the weight of the evidence suggests that there is a decrease in the percentage of $\mathrm{Y}$ cells in the deprived laminae of monocularly deprived cats. This loss of Y-cells does not appear to be an artifact of electrode sampling bias (Friedlander et al., 1981) nor do the Y-cells simply degenerate (Kalil, 1980). Therefore, only two possibilities remain. The Y-cells are silenced or some of the Y-cells develop as X-cells (Sherman et al., 1972; Friedlander et al., 1982).

Reverse suture. We found that reverse suture well after the end of the critical period is not sufficient to cause any increase in the proportion of Y-cells in the deprived laminae of the LGN. This finding is in agreement with that of Sherman and Wilson (1981). However, Hoffmann and Holländer (1978) and Hoffmann and Cynader (1977) reported that reverse suture at 6 to 12 months of age does produce a significant increase in the proportion of $\mathrm{Y}$-cells in the initially deprived laminae. The age at which animals were reverse sutured and the postreversal survival period cannot account for this discrepancy. However, since the cats studied by Hoffmann and Cyander (1977) and Hoffmann and Holländer (1978) were forced to use the initially deprived eye on visual discrimination tasks, while the animals studied by Sherman and Wilson (1981) and in the present study were not, forced usage of the initially deprived eye may cause an increase in the proportion of $\mathrm{Y}$-cells in the reverse sutured cats, explaining the difference in results.

Enucleation. Hoffmann and Cynader (1977) previously reported an increase in the percentage of Y-cells in deprived LGN laminae when the nondeprived eye was removed at 6 months of age and the deprived eye was opened for 1 year. In the present study, we have confirmed this finding and have defined some of the conditions that are necessary and sufficient for the recovery. Neither removing the nondeprived eye alone (MD-DE cats) nor opening the deprived eye and closing the nondeprived eye (adult MD-RS cats) is sufficient for a recovery of the Y-cells to occur. Rather, both removing the nondeprived eye and allowing the deprived eye visual experience are necessary conditions. In addition, recovery of the Y-cell population is seen not only in young (4month-old) but also in adult (12- to 16 -month-old) monocularly deprived cats (MD-DE-O and adult MD-DE$O$ cats), and in both cases, recovery occurs within 3 months.

Since the sampling density of X-cells was unchanged in MD-DE-O animals, the increased proportion of Y-cells is due to a recovery of $\mathrm{Y}$-cells, not a loss of $\mathrm{X}$-cells. The recovery of the Y-cell population is surprisingly complete in these animals. The percentage of Y-cells returned to normal range whether individual tests or a battery of tests was used to classify cells. Furthermore, the percentage of cells in the MD-DE-O group that were perfect Y-cells (responding as Y-cells on all four tests) was similar to that seen in normal animals. Therefore, by every physiological measure that we have used, the population of Y-cells found in monocularly deprived cats that had the nondeprived eye removed and the deprived eye opened is indistinguishable from the population of Y-cells seen in normal cats. It would be interesting to know if the anatomical effects of monocular deprivation, such as alterations in neuronal morphology (Friedlander et al., 1982), cortical projections (Garey and Blakemore, 1977; Lin and Sherman, 1978; LeVay and Ferster, 1977), and the decrease in the number of large neurons without laminated bodies (LeVay and Ferster, 1977), also can be corrected by this procedure. If so, then the LGN of monocularly deprived cats is capable of an amazing degree of plasticity, to the point of remodeling itself back into a normal functioning unit.

Relationship between percentage of Y.cells and cell size. Spear and Hickey (1979) found that, when the nondeprived eye is removed and the deprived eye remains sutured (MD-DE condition), neurons in deprived LGN laminae increase to nearly normal size over a period of 3 months and are significantly larger than cells in monocularly deprived cats (see also Garey and Dürsteller, 1975; Cragg et al., 1976). Under this same condition, we did not see an increase in the percentage of $Y$ cells. Thus, cell size increases when there is no increase in the proportion of Y-cells.

This result suggests that LGN soma size is not inextricably related to functional classification. However, an alternative possibility should be considered. Anatomical studies suggest that both X-and Y-cells in the lateral geniculate are smaller than normal after monocular deprivation, although the effect is greater among Y-cells (LeVay and Ferster, 1977). Therefore, it is possible that the increase in cell size in deprived laminae seen by Spear and Hickey (1979) is due to a growth of X-cells and not $\mathrm{Y}$-cells. That is, the soma sizes of the $\mathrm{Y}$-cells may remain small and their functional properties may remain abnor- 
mal. However, this seems unlikely because it would be necessary for the $\mathrm{X}$-cells to attain sizes that are much larger than normal to account for the overall increase in size that occurred. Therefore, it seems most likely that the soma sizes of Y-cells (as well as X-cells) increase in MD-DE cats, while their functional properties remain abnormal (silent, or developed into X-cell properties).

Previous studies also have reported a dissociation between the functional properties of LGN neurons and their soma sizes. In both dark-reared cats and binocularly lid-sutured cats, LGN cell size is virtually normal at the same time that there is a substantially lower than normal proportion of Y-cells (Sherman et al., 1972; Hickey et al., 1977; Kalil, 1978; Kratz et al., 1979). Thus, it appears that cells can change in size without markedly altering functional properties (MD-DE cats), and functional properties can change (or develop abnormally) without markedly affecting cell size (dark-reared and binocularly lidsutured cats).

Relationship between the LGN and striate cortex. When the results of the present study are compared with those in striate cortex (Kratz et al., 1976; Smith et al., 1978), two additional dissociations become apparent. First, removing the nondeprived eye alone (leaving the deprived eye closed) did not reverse the loss of Y-cells in the LGN; however, this procedure was sufficient to increase the ability of the deprived eye to drive striate cortex neurons (Kratz et al., 1976). Therefore, the increased ability of the deprived eye to drive cortical neurons is not dependent upon a recovery of the $\mathrm{Y}$-cell population in the LGN.

Second, when the nondeprived eye was removed and the deprived eye was allowed pattern vision for 3 months, there was a recovery of the $Y$-cell population from the low percentage found in monocularly deprived cats to that seen in normal animals. In contrast, Smith et al. (1978) found that there was no further improvement in cortical physiology when the deprived eye was allowed visual experience compared to when the deprived eye remained sutured following the removal of the nondeprived eye. There was neither a further increase in the number of striate cortex neurons that could be driven by the deprived eye nor was there any improvement in the receptive field properties of the responsive cells. Therefore, visual experience does not play a role in the recovery of striate cortex neurons but is necessary for the recovery of the Y-cells in the LGN.

Possible sites and mechanisms of effects of deprivation and subsequent recovery. These relationships between LGN physiology, LGN morphology, and striate cortex physiology point to several conclusions about the sites and mechanisms of effects of monocular deprivation and recovery from these effects following removal of inputs from the nondeprived eye. Evidence from previous studies suggests that the increased response of striate cortex cells to the deprived eye after removal of the nondeprived eye is due to a release from suppression mediated by the nondeprived eye (Kratz et al., 1976; Smith et al., 1978; Spear et al., 1980). The observation that this recovery can occur in cortex at the same time that there is no recovery in the LGN indicates that the release from interocular inhibition is due solely to intra- cortical mechanisms. This conclusion also is indicated by recent pharmacological studies, which show that local cortical administration of bicuculline can increase the proportion of striate cortex cells that respond to the deprived eye (Sillito et al., 1981; Burchfiel and Duffy, 1981).

The observation that LGN soma size can increase without a change in the functional classification of the cells suggests that two different, and potentially independent, mechanisms control these parameters. For example, cell size may simply be related to axon terminal spread or activity in cortex (Guillery and Stelzner, 1970; Guillery, 1972), independent of its functional classification. Monocular deprivation is known to decrease the ability of deprived LGN cells to activate cortical neurons (Wiesel and Hubel, 1963b, 1965; Blakemore and Van Sluyters, 1974; Kratz et al., 1976; Shatz and Stryker, 1978) and to decrease the terminal spread of deprived LGN afferents in cortex (Shatz et al., 1977; Shatz and Stryker, 1978), and this could lead to smaller neuronal somata to support the terminals. Removal of the nondeprived eye increases cortical activation by the deprived LGN terminals and perhaps increases the spread of these terminals in cortex (a possibility that has not yet been tested). Either of these effects might lead to larger supporting LGN cell bodies. In contrast, functional classification of LGN neurons may simply be related to retinogeniculate synaptic transmission efficiency, independent of the size of the postsynaplic cells. Indeed, there is evidence that retinogeniculate transmission is altered by rearing with monocular deprivation (Jones, 1980; Mitzdorf and Neumann, 1980; Mitzdorf and Singer, 1980) and evidence that this is due (at least in part) to changes in dendritic morphology of LGN neurons (Friedlander et al., 1982). Presumably, removing the nondeprived eye and allowing the deprived eye visual experience reverses these changes.

The mechanisms by which this reversal occurs in the LGN are unknown. However, the data of this and other studies suggest some preliminary hypotheses. The observation that it is necessary to remove the nondeprived eye to produce the reversal suggests that some interocular suppressive mechanism is at play. Interocular suppression is known to occur in the LGN of normal (Sanderson et al., 1971) and monocularly deprived (Sherman and Sanderson, 1972) cats, and this is eliminated by removing the nondeprived eye. The difference between the conditions that are necessary to produce functional recovery in the LGN and striate cortex suggests that any suppressive mechanisms that affect LGN cells occur within the LGN itself. One possibility is that interocular suppression occurs on the dendrites of the Y-cells, which are known to cross laminar borders and to be in a position to receive inputs from both eyes (Friedlander et al., 1981). It should be stressed, however, that mechanisms other than a release from interocular suppression also must be involved in the recovery of LGN Y-cells, since visual experience through the deprived eye is necessary for the recovery to occur. How a release from suppression triggers a recovery that depends upon visual experience and how visual experience produces the recovery are unknown. 


\section{References}

Bishop, P. O., W. Burke, and R. Davis (1962) The interpretation of the extracellular response of single lateral geniculate cells. J. Physiol. (Lond.) 162: 451-472.

Blakemore, C., and R. C. Van Sluyters (1974) Reversal of the physiological effects of monocular deprivation in kittens: Further evidence for a sensitive period. J. Physiol. (Lond.) 237: 195-216.

Bullier, J., and T. T. Norton (1979) X and Y relay cells in cat lateral geniculate nucleus: Quantitative analysis of receptivefield properties and classification. J. Neurophysiol. 42: 244-273.

Burchfiel, J. L., and F. H. Duffy (1981) Role of intracortical inhibition in deprivation amblyopia: Reversal by microiontophoresis of bicuculline. Brain Res. 206: 479-484.

Cleland, B. G., M. W. Dubin, and W. R. Levick (1971) Sustained and transient neurons in the cat's retina and lateral geniculate nucleus. J. Physiol. (Lond.) 217: 473-496.

Cragg, B., R. Anker, and Y. K. Wan (1976) The effect of age on the reversibility of cellular atrophy in the LGN of the cat following monocular deprivation: A test of two hypotheses about cell growth. J. Comp. Neurol. 168: 345-354.

Eysel, U. Th., O. -J. Grüsser, and K. -P. Hoffmann (1979) Monocular deprivation and signal transmission by $\mathrm{X}$ - and $\mathrm{Y}$ neurons of the cat lateral geniculate nucleus. Exp. Brain Res. 34: 521-539.

Fernald, R., and R. Chase (1971) An improved method for plotting retinal landmarks and focusing the eyes. Vision Res. 11: 95-96.

Friedlander, M. J., C. -S. Lin, L. R. Stanford, and S. M. Sherman (1981) Morphology of functionally identified neurons in lateral geniculate nucleus of the cat. J. Neurophysiol. 46: 80-129.

Friedlander, M. J., L. R. Stanford, and S. M. Sherman (1982) Effects of monocular deprivation on the structure-function relationship of individual neurons in the cat's lateral geniculate nucleus. J. Neurosci. 2: 321-330.

Garey, L. J., and C. Blakemore (1977) The effects of monocular deprivation on different neuronal classes in the lateral geniculate nucleus of the cat. Exp. Brain Res. 28: 259-278.

Garey, L. J., and M. R. Dürsteller (1975) Reversal of deprivation effects in the lateral geniculate nucleus of the cat. Neurosci. I e.t. 1: 19-24.

Guillery, R. W. (1972) Binocular competition in the control of geniculate cell growth. J. Comp. Neurol. 144: 117-130.

Guillery, R. W., and D. J. Stelzner (1970) The differential effects of unilateral lid closure upon the monocular and binocular segments of the dorsal lateral geniculate nucleus in the cat. J. Comp. Neurol. 139: 413-422.

Hickey, T. L., P. D. Spear, and K. E. Kratz (1977) Quantitative studies of cell size in the cat's dorsal lateral geniculate nucleus following visual deprivation. J. Comp. Neurol. 172: 265-282.

Hoffmann, K. -P., and M. Cynader (1977) Functional aspects of plasticity in the visual system of adult cats after early monocular deprivation. Philos. Trans. R. Soc. Lond. (Biol.) 278: 411-424.

Hoffmann, K. -P., and H. Holländer (1978) Physiological and morphological changes in cells of the lateral geniculate nucleus in monocularly-deprived and reverse-sutured cats. J. Comp. Neurol. 177: 145-158.

Hoffmann, K. -P., J. Stone, and S. M. Sherman (1972) Relay of receptive field properties in dorsal lateral geniculate nucleus of the cat. J. Neurophysiol. 35: 518-531.

Jones, K. R. (1980) Effects of visual deprivation on temporal modulation sensitivity of the optic tract, lateral geniculate nucleus and visual cortex of the cat. Doctoral dissertation, Florida State University, Tallahassee, FL.

Kalil, R. (1978) Dark rearing in the cat: Effects on visuomotor behavior and cell growth in the dorsal lateral geniculate nucleus. J. Comp. Neurol. 178: 451-468.

Kalil, R. (1980) A quantitative study of the effects of monocular enucleation and deprivation on cell growth in the dorsal lateral geniculate nucleus of the cat. J. Comp. Neurol. 189: 483-524.

Kratz, K. E., P. D. Spear, and D. C. Smith (1976) Postcriticalperiod reversal of effects of monocular deprivation on striate cortex cells in the cat. J. Neurophysiol. 39: 501-511.

Kratz, K. E., S. M. Sherman, and R. Kalil (1979) Lateral geniculate nucleus in dark-reared cats: Loss of $Y$ cells without changes in cell size. Science 203: 1353-1355.

LeVay, S., and D. Ferster (1977) Relay cell classes in the lateral geniculate nucleus of the cat and the effects of visual deprivation. J. Comp. Neurol. 172: 563-584.

Lin, C. -S., and S. M. Sherman (1978) Effects of early monocular eyelid suture upon development of relay cell classes in the cat's lateral geniculate nucleus. J. Comp. Neurol. 181: 809-832.

Mangel, S. C., J. R. Wilson, and S. M. Sherman (1980) Development of neuronal response properties in the cat lateral geniculate nucleus during monocular lid suture. Soc. Neurosci. Abstr. 6: 584 .

Mitzdorf, U., and G. Neumann (1980) Effects of monocular deprivation in the lateral geniculate nucleus of the cat: An analysis of evoked potentials. J. Physiol. (Lond.) 304: 221-230.

Mitzdorf, U, and W. Singer (1980) Monocular activation of visual cortex in normal and monocularly deprived cats: An analysis of evoked potentials. J. Physiol. (Lond.) 304: 203-220.

Mower, G. D., J. L. Burchfiel, and F. H. Duffy (1981) The effects of dark-rearing on the lateral geniculate nucleus. Dev. Brain Res. 1: 418-424.

Nikara, T., P. O. Bishop, and J. D. Pettigrew (1968) Analysis of retinal correspondence by studying receptive fields of binocular single units in cat striate cortex. Exp. Brain Res. 6: 353-372.

Sanderson, K. J. (1971) The projection of the visual field to the lateral geniculate and medial interlaminar nuclei in the cat. J. Comp. Neurol. 143: 101-118.

Sanderson, K. J., P. O. Bishop, and I. Darian-Smith (1971) The properties of the binocular receptive fields of lateral geniculate neurons. Exp. Brain Res. 13: 178-207.

Shapley, R., and S. Hochstein (1975) Visual spatial summation in two classes of geniculate cells. Nature 256: 411-413.

Shapley, R. M., and Y. -T. So (1980) Is there an effect of monocular deprivation on the proportions of $\mathrm{X}$ and $\mathrm{Y}$ cells in the cat lateral geniculate nucleus? Exp. Brain Res. 39: 41-48.

Shatz, C. J., and M. P. Stryker (1978) Ocular dominance in layer IV of the cat's visual cortex and the effects of monocular deprivation. J. Physiol. (Lond.) 281: 267-283.

Shatz, C. J., S. Lindstrom, and T. N. Wiesel (1977) The distribution of afferents representing the right and left eyes in the cat's visual cortex. Brain Res. 131: 103-116.

Sherman, S. M., and K. J. Sanderson (1972) Binocular interaction on cells of the dorsal lateral geniculate nucleus of visually deprived cats. Brain Res. 37: 126-131.

Sherman, S. M., and P. D. Spear (1982) Organization of the visual pathways in normal and visually deprived cats. Physiol. Rev., in press.

Sherman, S. M., and J. R. Wilson (1981) Further evidence for an early critical period in the development of cat's dorsal lateral geniculate nucleus. J. Comp. Neurol. 196: 459-470.

Sherman, S. M., K. -P. Hoffmann, and J. Stone (1972) Loss of a specific cell type from the dorsal lateral geniculate nucleus in visually deprived cats. J. Neurophysiol. 35: 532-541.

Sherman, S. M., J. R. Wilson, and R. W. Guillery (1975) Evidence that binocular competition affects the postnatal 
development of Y-cells in the cat's lateral geniculate nucleus. Brain Res. 100: 441-444.

Sillito, A. M., J. A. Kemp, and C. Blakemore (1981) The role of GABAergic inhibition in the cortical effects of monocular deprivation. Nature 291: 318-320.

Smith, D. C., P. D. Spear, and K. E. Kratz (1978) Role of visual experience in postcritical period reversal of effects of monocular deprivation in cat striate cortex. J. Comp. Neurol. 178: 313-328.

Spear, P. D., and T. L. Hickey (1979) Postcritical-period reversal of effects of monocular deprivation on dorsal lateral geniculate cell size in the cat. J. Comp. Neurol. 185: 317-328.

Spear, P. D., and L. Tong (1980) Effects of monocular deprivation on neurons in cat's lateral suprasylvian visual area. I. Comparison of binocular and monocular segments. J. Neurophysiol. 44: 568-584.
Spcar, P. D., A. Langsetmo, and D. C. Smith (1980) Age-related changes in effects of monocular deprivation on cat striate cortex neurons. J. Neurophysiol. 43: 559-580.

Wiesel, T. N., and D. H. Hubel (1963a) Effects of visual deprivation on morphology and physiology of cells in the cat's lateral geniculate body. J. Neurophysiol. 26: 978-993.

Wiesel, T. N., and D. H. Hubel (1963b) Single-cell response in striate cortex of kittens deprived of vision in one eye. $J$. Neurophysiol. 26: 1003-1017.

Wiesel, T. N., and D. H. Hubel (1965) Comparison of the effects of unilateral and bilateral eye closure on cortical unit responses in kittens. J. Neurophysiol. 28: 1029-1040.

Wilson, P., M. Rowe, and J. Stone (1976) Properties of relay cells in cat's lateral geniculate nucleus: A comparison of Wcells with X- and Y-cells. J. Neurophysiol. 39: 1193-1209. 